\title{
Air-stable ambipolar organic transistors
}

\author{
Thomas D. Anthopoulos ${ }^{\text {a) }}$ \\ Department of Physics, Blackett Laboratory, Imperial College London, London SW7 2BW, United Kingdom
}

G. C. Anyfantis and G. C. Papavassiliou

Theoretical and Physical Chemistry Institute, National Hellenic Research Foundation, 48 Vassileos Constantinou Avenue, Athens 116-35, Greece

Dago M. de Leeuw

Philips Research Laboratories, High Tech Campus 4, 5656 AE Eindhoven, The Netherlands

(Received 11 January 2007; accepted 14 February 2007; published online 20 March 2007)

\begin{abstract}
The authors report on ambipolar organic transistors based on the soluble dithiolene derivative (diphenylethylenedithiolato)(1,3-dithiol-2-thione-4,5-dithiolato)nickel [Ni(dpedt)(dmit)]. Due to its small band gap, efficient injection of holes and electrons from gold source/drain electrodes is possible. Both carrier mobilities are estimated to be approximately equal with maximum value on the order of $10^{-4} \mathrm{~cm}^{2} / \mathrm{V} \mathrm{s}$. The transistors exhibit excellent ambient stability with a shelve lifetime exceeding 3 months. The pronounced stability of $\mathrm{Ni}(\mathrm{dpedt})(\mathrm{dmit})$ as well as of several other molecules studied here is correlated to their redox potential. The present findings can be used as a general guide towards design and synthesis of air-stable ambipolar $/ n$-channel molecules. () 2007 American Institute of Physics. [DOI: 10.1063/1.2715028]
\end{abstract}

Ambipolar charge transport in organic semiconductors is an interesting material property both for fundamental research and for technological applications. In recent years ambipolar transport has been exploited in organic field-effect transistors (OFETs) for the fabrication of complementarylike logic circuits ${ }^{1-5}$ and bifunctional devices such as lightemitting OFETs. ${ }^{6-9}$ The majority of ambipolar organic transistors demonstrated so far are based on bulk heterojunction systems where an electron transporting ( $n$-channel) material is mixed/blended with a hole transporting ( $p$-channel) one, either through solution blending ${ }^{1,2}$ or thermal coevaporation, ${ }^{8}$ to form the heterogeneous ambipolar semiconductive layer. Bilayer-type ambipolar organic transistors based on the $p / n$ heterostructure concept have also been demonstrated. ${ }^{10}$ Realization of ambipolar organic OFETs based on a single semiconductor, on the other hand, has been proven to be much more difficult mainly due to the poor environmental stability of the $n$-channel operation. ${ }^{1,5,9,11,12}$ Only recently single component air-stable ambipolar OFETs and logic circuits have been demonstrated. ${ }^{4,13}$ In these studies the near infrared absorbing dithiolene derivative bis [4-dimethylaminodithiobenzyl]-nickel was employed as the semiconductor layer. In spite of the very promising preliminary results, however, new ambipolar molecules with comparable environmental stability have yet to be demonstrated. To this end the synthesis of such molecules is of primary importance.

Here, we extend our previous work on air-stable ambipolar organic transistors and we report on devices based on the dithiolene derivative diphenylethylenedithiolate (diphenylethylenedithiolato)(1,3-dithiol-2-thione-4,5-dithiolato)nickel [Ni(dpedt)(dmit)]. Despite the fact that semiconductor deposition and transistor characterization are performed under ambient air and light, no degradation on device performance is observed for an exposure period of 3

\footnotetext{
a) Author to whom correspondence should be addressed; electronic mail:
} thomas.anthopoulos@imperial.ac.uk months. The latter is attributed to the high electron affinity of $\mathrm{Ni}(\mathrm{dpedt})$ (dmit), making it less susceptible to atmospheric oxidants. The present findings can be viewed as a significant step toward designing and synthesis of environmentally stable molecules for application in organic electronics.

Field-effect transistors were made using heavily doped p-type $\mathrm{Si}$ wafers as the common gate electrode with a $200 \mathrm{~nm}$ thermally oxidized $\mathrm{SiO}_{2}$ layer as the gate dielectric. Using conventional photolithography, gold source and drain electrodes were defined in a bottom-contact configuration with channel width $(W)$ of $1000 \mu \mathrm{m}$ and length $(L)$ in the range $0.75-40 \mu \mathrm{m}$. A $10 \mathrm{~nm}$ titanium was used as an adhesion interlayer for the gold on $\mathrm{SiO}_{2}$. Then, $\mathrm{SiO}_{2}$ was treated with the primer hexamethyldisilazane prior to semiconductor deposition in order to passivate its surface. Films of $\mathrm{Ni}(\mathrm{d}-$ pedt)(dmit) were then drop cast on top of the prepatterned transistor substrates from a $1 \mathrm{mg} / \mathrm{ml}$ dichloromethane solution. Electrical measurements were performed in ambient conditions at room temperature using an HP 4156C semiconductor parameter analyzer.

The organometallic complex Ni(dpedt)(dmit) (Fig. 1, inset) was prepared by the cross-coupling-type method ${ }^{14}$ using the ligands diphenylethylenedithiolate (dpedt) (Ref. 15) and 1,3-dithiol-2-thione-4,5-dithiolate (dmit) (Ref. 16) in the presence of $\mathrm{NiCl}_{2}$. The required asymmetrical complex was separated from the symmetrical by-products, namely, $\mathrm{Ni}(\mathrm{dpedt})_{2}$ and $\mathrm{Ni}(\mathrm{dmit})_{2}$, by liquid column chromatography. The latter is a dark-green microcrystalline material with melting point of $>240{ }^{\circ} \mathrm{C}$ and molecular weight of 496.6 . Furthermore, it is found to be soluble in $\mathrm{CH}_{2} \mathrm{Cl}_{2}, \mathrm{CS}_{2}$, and various other organic solvents with a strong absorption band (in $\mathrm{CS}_{2}$ solution) at $974 \mathrm{~nm} .{ }^{17}$ Figure 1 shows the optical absorption spectrum for a spin coated film of $\mathrm{Ni}(\mathrm{dpedt})(\mathrm{d}-$ mit) deposited on quartz substrate directly from a $\mathrm{CS}_{2}$ solution. From the onset of the absorption in the solid film, the optical band gap can be approximated, yielding a value of $0.85 \mathrm{eV}$. The redox potentials for $\mathrm{Ni}(\mathrm{dpedt})(\mathrm{dmit})$ were also measured, yielding $E_{1 / 2}(2-/ 1-)=-0.497 \mathrm{~V}$ and $E_{1 / 2}(1$ 


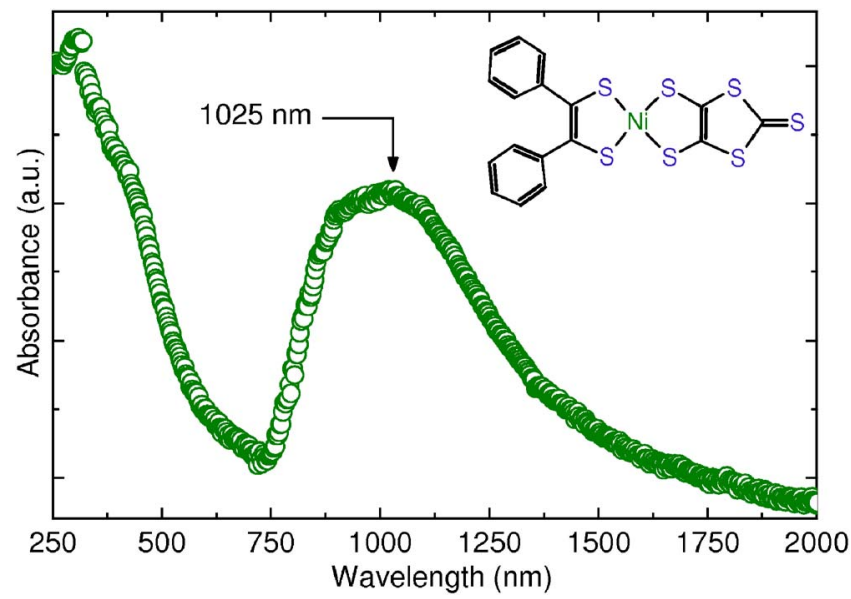

FIG. 1. (Color online) Absorption spectra of a Ni(dpedt)(dmit) film spin coated on quartz substrate from a $\mathrm{CS}_{2}$ solution. Inset: Molecular structure of the $\mathrm{Ni}(\mathrm{dpedt})(\mathrm{dmit})$ derivative.

$-/ 0)=0.122 \mathrm{~V}$ in $\mathrm{CH}_{3} \mathrm{CN}$ vs saturated colomel electrode (SCE), respectively. ${ }^{18,19}$ By combining the optical and electrochemical data, the energy levels of the lowest unoccupied molecular orbitals (LUMOs) and highest occupied molecular orbitals can be estimated, ${ }^{20-23}$ yielding 4.43 and $5.28 \mathrm{eV}$, respectively.

To test the potential of $\mathrm{Ni}(\mathrm{dpedt})$ (dmit) for practical transistor applications, we have fabricated and characterized a number of bottom-contact OFETs. Figure 2 shows the output characteristics obtained from an OFET $(L=10 \mu \mathrm{m}$ and $W=10 \mathrm{~mm}$ ) fabricated and characterized in ambient conditions. Despite the device exposure to air, strong hole and electron accumulation is observed under appropriate biasing conditions. In particular, for negative drain $\left(V_{D}\right)$ and gate $\left(V_{G}\right)$ voltages, accumulation of holes is evident. From these curves a maximum hole mobility of approximately $10^{-4} \mathrm{~cm}^{2} / \mathrm{V} \mathrm{s}$ was derived. When $V_{D}$ and $V_{G}$ are biased positively, electron accumulation occurs with a maximum calculated mobility on the order of $3 \times 10^{-4} \mathrm{~cm}^{2} / \mathrm{V} \mathrm{s}$. The on-off current ratio, calculated from the transfer characteristics of our best performing devices, is on the order of $10^{2}-10^{3}$. This relatively low value is ascribed to the characteristically small band gap $(\sim 0.85 \mathrm{eV})$ of $\mathrm{Ni}(\mathrm{dpedt})(\mathrm{dmit})$ that affect the

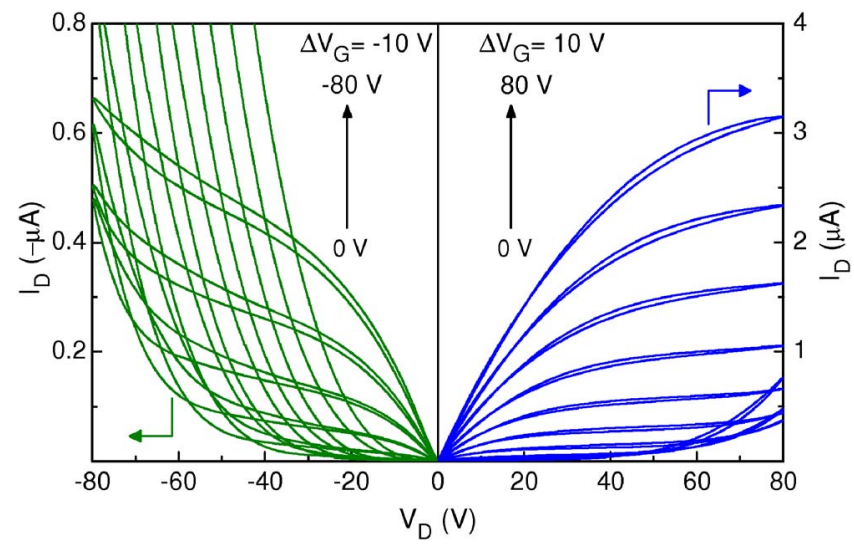

FIG. 2. (Color online) Output characteristics of a Ni(dpedt)(dmit) transistor with channel length and width of $L=10 \mu \mathrm{m}$ and $W=10 \mathrm{~mm}$, respectively. Electrical characterization was performed in ambient conditions at room temperature. We note that the electrical characteristics remain the same even after exposure of the device to ambient atmosphere (shelve storage) for a

period of 3 months.
Downloaded 25 Apr 2008 to 155.198.4.89. Redistribution subject to AIP license or copyright; see http://apl.aip.org/apl/copyright.jsp

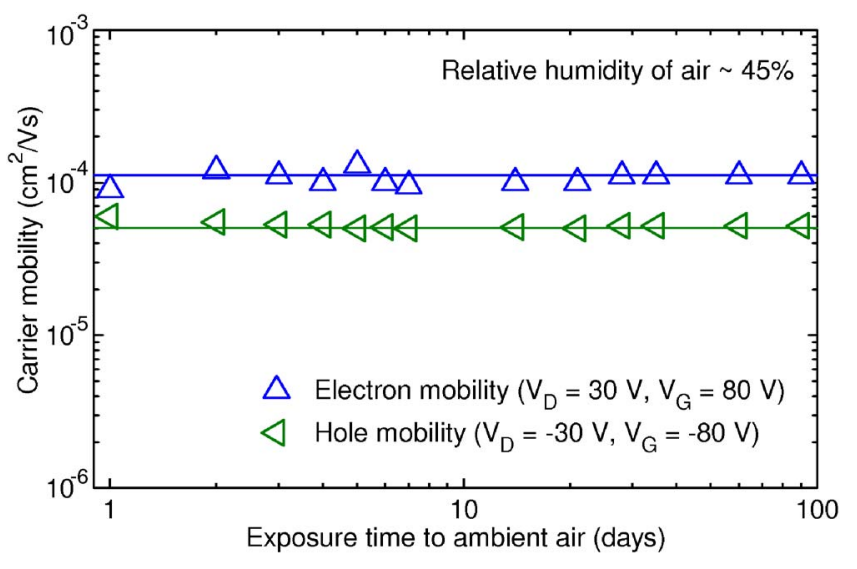

FIG. 3. (Color online) Hole and electron mobilities calculated in the saturation regime vs exposure time of the $\mathrm{Ni}(\mathrm{dpedt})(\mathrm{dmit})$ transistor to ambient air and light. Relative humidity of the ambient air was measured at approximately $45 \%$.

switching characteristics of the transistors due to significant ambipolar carrier injection and transport through the channel. Moreover, from the linear dependence of $I_{D}$ on $\left|V_{D}\right|$, observed at low bias, we conclude that gold electrodes provide nearly Ohmic contact for both hole and electron injections. The latter is attributed to the small band gap of $\mathrm{Ni}(\mathrm{d}-$ pedt)(dmit). Furthermore, the devices exhibit minimal hysteresis without noticeable changes before (tested in high vacuum) and after exposure to ambient air.

Despite the low carrier mobility values, the apparent environmental stability of the $\mathrm{Ni}(\mathrm{dpedt})$ (dmit) transistors is unprecedented. This is clearly demonstrated in Fig. 3, where the mobility of holes and electrons, calculated at $V_{G}= \pm 80 \mathrm{~V}$ and $V_{D}= \pm 30 \mathrm{~V}$, is plotted versus exposure time to ambient air (i.e., shelve storage without any electrical bias applied) at a relative humidity of $45 \%$. As can be seen no noticeable degradation on either electron or hole mobility is observed. Although the stability of the $p$-channel does not come as a surprise the $n$-channel stability does as it has been reported only for a handful of organic molecules. ${ }^{4,13,24-27}$ In an effort to elucidate the origin of the $n$-channel stability we have studied a series of organic molecules with different electrochemical characteristics (Fig. 4). Our results indicate that molecules with LUMO energies higher than approximately $4 \mathrm{eV}$ (blue arrow) are far less sensitive to atmospheric air than molecules characterized by a lower LUMO (green arrow). In particular, we found that $\mathrm{C}_{60}$ and $\mathrm{C}_{70}$ fullerene derivatives, such as $[6,6]$-phenyl- $\mathrm{C}_{61}$-butyric acid methyl ester and $[6,6]$-phenyl- $\mathrm{C}_{71}$-butyric acid methyl ester, as well as pristine $\mathrm{C}_{60}$, all with LUMOs $<4 \mathrm{eV}$, are highly sensitive to atmospheric air. ${ }^{3,11}$ On the contrary, molecules with LUMOs $>4 \mathrm{eV}$, such as $[6,6]$-phenyl- $\mathrm{C}_{85}$-butyric acid methyl ester, ${ }^{27}$ dithiolene derivatives, ${ }^{4}$ and perfluorinated copper phthalocyanine, ${ }^{24}$ exhibit high $n$-channel stability. Our observation not only holds for the molecules shown in Fig. 4 but is also valid for most air-stable $n$-channel organic semiconductors reported in the literature, e.g., naphthalene/ perylene derivatives, ${ }^{25}$ cyano-polycyclic organic semiconductors, ${ }^{26}$ and various others.

The critical issue of environmental stability of $n$-channel organic semiconductors has been initially addressed by de Leeuw et al. back in $1997 .{ }^{28}$ In this early study the workers have identified oxygen $\left(\mathrm{O}_{2}\right)$ and water $\left(\mathrm{H}_{2} \mathrm{O}\right)$ as the main atmospheric oxidants responsible for $n$-channel degradation P license or copyright; see http://apl.aip.org/apl/copyright.jsp 


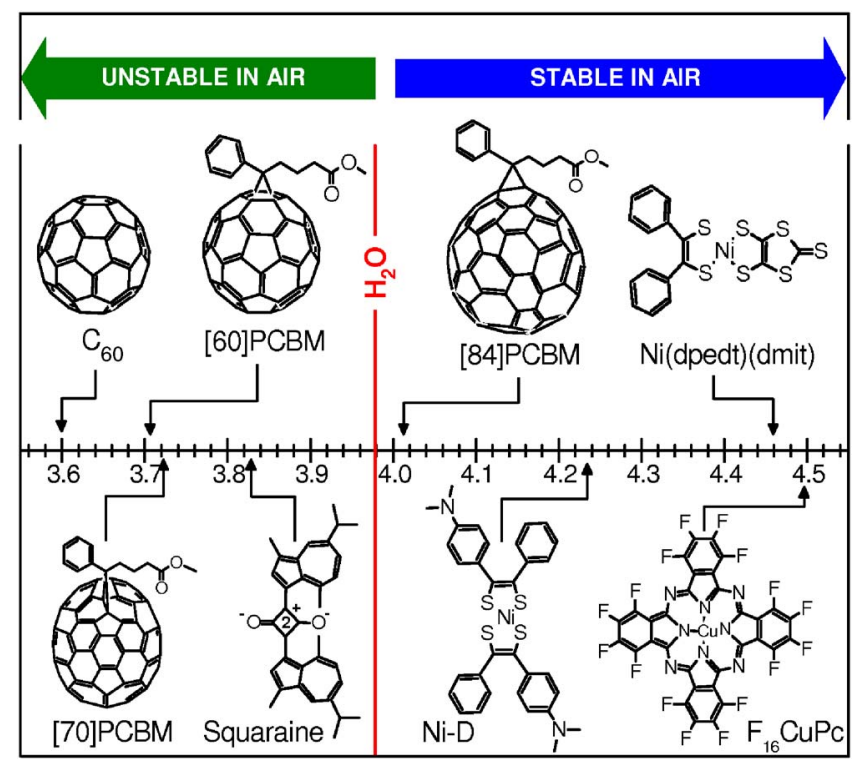

LUMO energy $(\mathrm{eV})$

FIG. 4. (Color online) LUMO energy levels of the various organic molecules studied. The red line located at an energy level of $3.98 \mathrm{eV}$ indicates the calculated redox potential $(-0.658 \mathrm{~V}$ vs SCE) for water reduction at a $p \mathrm{H}=7$ (Ref. 28). The green arrow indicates the LUMO energy range for unstable $n$-channel molecules toward ambient air. The blue arrow indicates the LUMO energy range for air-stable $n$-channel molecules. As can be seen a good agreement between theoretical prediction and the experimental results is observed.

upon exposure to atmospheric air. Specifically, they have calculated the limits of the reduction potential at which a $n$-channel molecule becomes unstable toward reduction of $\mathrm{O}_{2}$ and $\mathrm{H}_{2} \mathrm{O}$. By assuming $\mathrm{H}_{2} \mathrm{O}(p \mathrm{H}=7)$ to be the main atmospheric oxidant contributor, this redox limit was calculated, yielding $-0.658 \mathrm{~V}$ versus SCE. This potential can be translated to an electron affinity of approximately $4 \mathrm{eV}$ (red line in Fig. 4), implying that molecules with LUMO $<4 \mathrm{eV}$ are expected to be unstable toward reduction of $\mathrm{H}_{2} \mathrm{O}$ due to the redox reaction. Under these circumstances $\mathrm{H}_{2} \mathrm{O}$ molecules act as electron traps, thus reducing the electron current that flows through the channel. This prediction is in good agreement with our experimental findings presented in Fig. 4.

So far we have not been able to determine whether the instability of the $n$-channel molecules investigated here is solely due to $\mathrm{H}_{2} \mathrm{O}$ or due to a combination of more atmospheric oxidants, i.e., $\mathrm{O}_{2}$, hydrogen peroxide, ozone, etc., and is beyond the scope of the present study. Further work, currently under way, is focusing on addressing this issue by looking on the relation between the electron affinity of various $n$-channel molecules and the electrochemical characteristics of individual atmospheric oxidants and their effects on device performance during shelve storage but also under continuous operating conditions (i.e., under bias stressing).

In summary, we have demonstrated ambipolar OFETs based on a soluble dithiolene derivative. Although the carrier mobilities in this particular molecule are moderate, the environmental stability of the OFETs, and particularly the $n$-channel operation, is unprecedented. Based on this result together with further experimental data obtained from several different organic semiconductors, we were able to correlate the $n$-channel stability of these molecules to their electrochemical characteristics. Our findings are inline with earlier predictions on the effects of atmospheric oxidants ${ }^{28}$ and suggest that for the synthesis of air-stable $n$-channel materials one must aim for organic molecules with electron affinity $>4 \mathrm{eV}$.

The authors are grateful to the Engineering and Physical Sciences Research Council (EPSRC) for financial support. One of the authors (T.D.A.) is an EPSRC Advanced Research Fellow. Two of the authors (G.C.A. and G.C.P.) acknowledge support from GSRT-Ministry of Development in Greece through the Excellence in the Research Institutes Grant No. 0684.

${ }^{1}$ E. J. Meijer, D. M. de Leeuw, S. Setayesh, E. Van Veenendaal, B.-H. Huisman, P. W. M. Blom, J. C. Hummelen, U. Scherf, and T. M. Klapwijk, Nat. Mater. 2, 678 (2003).

${ }^{2}$ T. D. Anthopoulos, D. M. de Leeuw, S. Setayesh, E. Cantatore, C. Tanase, P. W. M. Blom, and J. C. Hummelen, Mater. Res. Soc. Symp. Proc. 871E, I11.9 (2005).

${ }^{3}$ T. D. Anthopoulos, D. M. de Leeuw, E. Cantatore, S. Setayesh, E. J. Meijer, C. Tanase, J. C. Hummelen, and P. W. M. Blom, Appl. Phys. Lett. 85, 4205 (2004).

${ }^{4}$ T. D. Anthopoulos, S. Setayesh, E. C. P. Smits, M. Cölle, B. de Boer, E. Cantatore, P. W. M. Blom, and D. M. de Leeuw, Adv. Mater. (Weinheim, Ger.) 18, 1900 (2006).

${ }^{5}$ T. D. Anthopoulos, D. M. de Leeuw, E. Cantatore, P. van't Hof, J. Alma, and J. C. Hummelen, J. Appl. Phys. 98, 054503 (2005).

${ }^{6}$ J. Zaumzeil, R. H. Friend, and H. Sirringhaus, Nat. Mater. 5, 69 (2006).

${ }^{7}$ J. S. Swensen, C. Soci, and A. J. Heeger, Appl. Phys. Lett. 87, 253511 (2005).

${ }^{8}$ M. A. Loi, C. Rost-Bietsch, M. Murgia, S. Karg, W. Riess, and M. Muccini, Adv. Funct. Mater. 16, 41 (2006).

${ }^{9}$ E. C. P. Smits, S. Setayesh, T. D. Anthopoulos, M. Buechel, W. Nijssen, R. Coehoorn, P. W. M. Blom, B. de Boer, and D. M. de Leeuw, Adv. Mater. (Weinheim, Ger.) 19, 734 (2007).

${ }^{10}$ C. Rost, D. J. Gundlach, S. Karg, and W. Rieb, J. Appl. Phys. 95, 5782 (2004).

${ }^{11}$ T. D. Anthopoulos, C. Tanase, S. Setayesh, E. J. Meijer, J. C. Hummelen, P. W. M. Blom, and D. M. de Leeuw, Adv. Mater. (Weinheim, Ger.) 16, 2174 (2004).

${ }^{12}$ L.-L. Chua, J. Zaumseil, J.-F. Chang, E. C.-W. Ou, P. K.-H. Ho, H. Sirringhaus, and R. H. Friend, Nature (London) 434, 194 (2005).

${ }^{13}$ E. C. P. Smits, T. D. Anthopoulos, S. Setayesh, B. de Boer, E. van Veenendaal, R. Coehoorn, P. W. M. Blom, and D. M. de Leeuw, Phys. Rev. B 73, 205316 (2006).

${ }^{14}$ G. C. Papavassiliou and G. C. Anyfantis, Z. Naturforsch., B: Chem. Sci. 60b, 811 (2005).

${ }^{15}$ A. K. Bhattacharya and A. E. Hortmann, J. Org. Chem. 39, 95 (1974).

${ }^{16}$ G. Steimecke, H.-J. Sieler, R. Kirmse, and E. Hoyer, Phosphorus, Sulfur Silicon Relat. Elem. 7, 49 (1978).

${ }^{17}$ P. Aloukos, S. Couris, J. B. Koutselas, G. C. Anyfantis, and G. C. Papavassiliou, Chem. Phys. Lett. 428, 109 (2006).

${ }^{18}$ A. Davison, J. A. McCleverty, E. T. Shawl, and E. J. Whatron, J. Am. Chem. Soc. 89, 830 (1967).

${ }^{19}$ G. C. Papavassiliou and K. Mayer (unpublished).

${ }^{20}$ X. Gao, W. Wu, Y. Liu, S. Jiao, W. Qiu, G. Yu, L. Wang, and D. Zhu, J. Mater. Chem. 17, 736 (2007).

${ }^{21}$ M. Nomura, T. Cauchy, M. Geoffrey, P. Adkine, and M. Formigue, Inorg. Chem. 45, 8194 (2006).

${ }^{22}$ K. Wang, Prog. Inorg. Chem. 52, 267 (2004).

${ }^{23}$ G. A. Bowmaker, P. D. W. Boyd, and G. K. Campbell, Inorg. Chem. 22, 1208 (1983).

${ }^{24}$ Z. Bao, A. J. Lovinger, and J. Brown, J. Am. Chem. Soc. 120, 207 (1998).

${ }^{25}$ H. E. Katz, A. J. Lovinger, J. Johnson, C. Kloc, T. Siegrist, W. Li, Y.-Y. Lin, and A. Dodabalapur, Nature (London) 404, 478 (2000).

${ }^{26}$ B. A. Jones, M. J. Ahrens, M.-H. Yoon, A. Facchetti, T. J. Marks, and M. R. Wasielewski, Angew. Chem., Int. Ed. 43, 6363 (2004).

${ }^{27}$ T. D. Anthopoulos, F. Kooistra, H. J. Wondergem, D. Kronholm, J. C. Hummelen, and D. M. de Leeuw, Adv. Mater. (Weinheim, Ger.) 18, 1679 (2006).

${ }^{28}$ D. M. de Leeuw, M. M. J. Simenon, A. R. Brown, and R. E. F. Einerhand, Synth. Met. 87, 53 (1997). 